\title{
Problematic video game use as an emotional coping strategy: Evidence from a sample of MMORPG gamers
}

\author{
MARIA DI BLASI ${ }^{1}$, ALESSANDRO GIARDINA ${ }^{1}$, CECILIA GIORDANO $^{1}$, GIANLUCA LO COCO $^{1}$, CRISPINO TOSTO $^{2}$, \\ JOEL BILLIEUX ${ }^{3}$ and ADRIANO SCHIMMENTI ${ }^{4}$
}

\author{
${ }^{1}$ Department of Psychological and Educational Sciences, University of Palermo, Palermo, Italy \\ ${ }^{2}$ Istituto per le Tecnologie Didattiche, Consiglio Nazionale delle Ricerche, Palermo, Italy \\ ${ }^{3}$ Addictive and Compulsive Behaviours Laboratory, Institute for Health and Behaviours, University of Luxembourg, \\ Esch-sur-Alzette, Luxembourg \\ ${ }^{4}$ Faculty of Human and Social Sciences, UKE - Kore University of Enna, Enna, Italy
}

(Received: September 2, 2018; revised manuscript received: November 20, 2018; accepted: December 23, 2018)

\begin{abstract}
Background: A positive relationship between problematic gaming and escapism motivation to play video games has been well established, suggesting that problematic gaming may result from attempts to deal with negative emotions. However, to date, no study has examined how emotion dysregulation affects both escapism motives and problematic gaming patterns. Methods: Difficulties in emotion regulation, escapism, and problematic involvement with video games were assessed in a sample of 390 World of Warcraft players. A structural equation modeling framework was used to test the hypothesis that escapism mediates the relationship between emotion dysregulation and problematic gaming. Results: Statistical analyses showed that difficulties in emotion regulation predicted both escapism motives and problematic gaming, and that escapism partially mediated this relationship. Conclusion: Our findings support the view that problematic players are likely to escape in online games as a maladaptive coping strategy for dealing with adverse emotional experiences.
\end{abstract}

Keywords: problematic gaming, emotion regulation, Internet gaming disorder, escapism, MMORPG, gaming disorder

\section{INTRODUCTION}

Massively multiplayer online role-playing games (MMORPGs) are virtual environments in which players can interact with each other through customizable avatars, co-operating, role-playing, and competing with millions of players around the world. Previous literature on problematic gaming $(\mathrm{PG})$ has largely focused on MMORPGs. PG is currently considered a potential disorder, listed within "Emerging Measures and Models" (Section III) in the most recent edition of the Diagnostic and Statistical Manual of Mental Disorders (DSM-5; American Psychiatric Association, 2013) under the label Internet gaming disorder (IGD). Furthermore, the International Classification of Diseases (World Health Organization, 2018) includes Gaming Disorder in its section devoted to disorders resulting from addictive behaviors. Nevertheless, what exactly constitutes PG is still a topic of debate (King et al., 2018; Van Rooij et al., 2018). One concern arises from the risk of pathologizing healthy, "highly engaged" gamers who could fit the diagnostic criteria for IGD without experiencing significant life impairment (Deleuze, Long, Liu, Maurage, \& Billieux, 2018). Moreover, it remains unclear whether there is a causal relationship between life impairments and addictive-like gaming behavior (Kardefelt-Winther, 2014a, 2014b; Snodgrass et al., 2014; Van Rooij et al., 2018).

Although PG has often been conceptualized within a biomedical model of addiction (Petry et al., 2014), alternative etiological hypotheses have emerged. These include PG resulting from maladaptive coping strategies displayed to deal with negative affect states (Maroney, Williams, Thomas, Skues, \& Moulding, 2018; Reinecke, 2009; Schimmenti \& Caretti, 2010; Snodgrass et al., 2018). In this respect, Kardefelt-Winther (2014b) proposed that some individuals might use the online environment to alleviate negative feelings arising from stressful or adverse life situations, potentially leading to problematic use and addictive-like symptoms. Therefore, PG may represent a maladaptive coping strategy for individuals with limited self-regulation skills.

Emotion dysregulation (ED) and problematic gaming (PG) In the past two decades, the construct of ED has received growing interest in psychology and psychopathology. ED

* Corresponding author: Maria Di Blasi; Department of Psychological and Educational Sciences, University of Palermo, Viale delle Scienze, Edificio 15, Palermo 90100, Italy; Phone: +39 091238 97717; Fax: +39 091651 3825; E-mail: maria.diblasi@unipa.it

This is an open-access article distributed under the terms of the Creative Commons Attribution-NonCommercial 4.0 International License, which permits unrestricted use, distribution, and reproduction in any medium for non-commercial purposes, provided the original author and source are credited, a link to the CC License is provided, and changes - if any - are indicated. 
has been related to several types of psychopathological and relational problems (D'Agostino, Covanti, Monti, \& Starcevic, 2017; Dimaggio et al., 2017; Gross \& Jazaieri, 2014), leading some authors to consider it a hallmark of psychopathology (Beauchaine, Gatzke-Kopp, \& Mead, 2007). Emotion regulation is generally referred to as a set of psychological processes aimed at differentiating, recognizing, and modulating feelings with flexibility and according to environmental and relational stimuli (David, 2016; Fonagy, Gergely, Jurist, \& Target, 2002; Gross \& Thompson, 2007).

Emotional processing and emotion regulation have been widely analyzed in previous studies of smartphone, social networks, and general Internet use, showing both a positive effect on well-being (Elhai et al., 2018; Hoffner \& Lee, 2015; Kardefelt-Winther, 2014a) and a link to problematic Internet use (Casale, Caplan, \& Fioravanti, 2016; Hormes, Kearns, \& Timko, 2014; Schimmenti, Starcevic, Gervasi, Deleuze, \& Billieux, 2018; Yildiz, 2017). In the context of online gaming, many studies have reported a higher use of video games for emotion regulation purposes (Gaetan, Bréjard, \& Bonnet, 2016; Hemenover \& Bowman, 2018; Hussain \& Griffiths, 2009; Villani et al., 2018). For example, Villani et al. (2018) suggested that some video game features, such as interactivity, the sense of mastery, and the ability to deal safely with failure and experiment with identity, may play a part in facilitating emotion regulation.

Despite the conflicting evidence, few studies have addressed the role of ED in PG (Billieux et al., 2011; Estévez, Jáuregui, Sánchez-Marcos, López-González, \& Griffiths, 2017; Yen et al., 2018). Billieux et al. (2011) found that a tendency to act rashly when experiencing intense negative feelings was the main impulsivity dimension promoting problematic involvement in World of Warcraft (WoW) in a sample of gamers. Similarly, Estévez et al. (2017) showed that a lack of emotional clarity and control over emotional responses predicted problematic video game involvement in their sample. Therefore, it might be hypothesized that some people with emotion regulation difficulties use video game environments to deal with negative affectivity, thus increasing the risk of negative consequences (Kardefelt-Winther, 2014b). Clearly, there is a need to address the paucity of research on the role of ED among problematic gamers.

\section{Escapism motivations to play and emotional coping}

The construct of motivations to play (Yee, 2006) could be critical in explaining the relationship between ED and PG. For example, Billieux et al. (2013) found that motivations to play have specific, meaningful associations with in-game behaviors, suggesting that psychological motives are reliable indices of players' interests and needs.

Among the various motivations to play, escapism has been studied extensively. Escapism refers to the involvement in video games to relax or to distract oneself from real-life problems (Yee, 2006). It may represent one of the main features contributing to the enjoyment of online games and is not necessarily related to negative outcomes
(Bowditch, Chapman, \& Naweed, 2018; Hussain \& Griffiths, 2009; Kardefelt-Winther, 2014c). Indeed, Kuo, Lutz, and Hiler (2016) conceived escapism as an "active," emotion-focused, coping mechanism that brings relief from stress and a sense of efficacy and empowerment to players' lives. However, several studies have shown escapism motivation to be one of the strongest predictors of PG with regard to its avoidant, passive, and disengaging nature (Ballabio et al., 2017; Billieux et al., 2013; Bowditch et al., 2018; Kuss, Louws, \& Wiers, 2012; Schimmenti, Infanti, Badoud, Laloyaux, \& Billieux, 2017; ZanettaDauriat et al., 2011).

To account for this contradiction, some authors have argued that the negative potential of escapism is related to its interactions with other vulnerability factors, such as psychological distress, poor psychosocial well-being, or poor coping resources (Ballabio et al., 2017; Bowditch et al., 2018; Demetrovics et al., 2011; Kardefelt-Winther, $2014 b, 2014 c)$. Moreover, some studies have suggested that an interaction between negative affect and escapism is likely to play a pivotal role in PG (Billieux et al., 2015; Bowditch et al., 2018; Chang, Hsieh, \& Lin, 2018; Kardefelt-Winther, 2014a; Maroney et al., 2018). For example, Kardefelt-Winther (2014a) showed that escapism mediated the relationship between distress and problematic use of WoW. Another study (Király et al., 2015) suggested that psychiatric symptoms were both directly and indirectly (via escapism and competition motives, respectively) negatively associated with $\mathrm{PG}$ in a sample of online gamers. In addition, Billieux et al. (2015) postulated that among participants characterized by increased negative affect in their sample of 1,057 WoW players, PG was probably the result of a maladaptive coping strategy to overcome negative affect and negative life events. Finally, Maroney et al. (2018) recently found that escapism motivations partially mediated the significant effects of depression, loneliness, and social anxiety on PG among first-person shooter and MMORPG players. However, to date, no studies have explored the link between ED and escapism motivations in problematic MMORPGs use.

\section{The present study}

The aim of this study was to test the relationships between ED, escapism motivations, and PG. More specifically, we hypothesized that WoW players with higher levels of ED use video games to escape negative affect, and that this greater need to escape into virtual reality in turn triggers PG. Hence, the present investigation has the potential to shed light on the underlying mechanisms of $\mathrm{PG}$ and thus to inform clinical practice. According to the theoretical framework of the study, three operational hypotheses can be formulated:

H1: Emotion dysregulation statistically predicts problematic gaming.

H2: Emotion dysregulation statistically predicts escapism.

H3: Emotion dysregulation statistically predicts problematic gaming via escapism. 


\section{METHODS}

\section{Participants and procedure}

Since every game genre has specific features and structural characteristics that are likely to have confounding effects on findings, we contacted players of the MMORPG WoW only. WoW is the most popular title in the MMORPGs genre and still counts millions of players around the world today. The game has in fact been the subject of several previous studies designed to assess motivations to play MMORPG and potential psychological factors associated with problematic gaming (Billieux et al., 2013; Bowditch et al., 2018; Yee, 2006). In WoW, players interact with each other through customizable avatars within the heroic-fantasy world of Azeroth. Much of the gameplay revolves around co-operation (player vs. environment) or competition (player vs. player) with other players (often via virtual social networks called "guilds"), in order to complete quests, improve character skills and items, and achieve a better in-game ranking.

Participants were recruited through an advertisement posted on official WoW forums, Facebook groups and pages, and general video game forums. The advertisement briefly explained the aim of the study and invited players to participate through an online survey. The survey started in May 2017 and ended June 2018. Inclusion criteria were being fluent Italian speakers, active WoW players, and aged 18 years or older. Anonymity was assured (no data on the gamers' identification, including their Internet Protocol address, were collected). Information on sociodemographic variables including sex, age, and ethnicity, as well as gamerelated variables, such as participants' character's race (e.g., elf, human, orc), faction (horde or alliance), character level, self-reported weekly hours spent playing, and the number of months played, were collected through a structured questionnaire administered along with standardized self-reports. Self-reported weekly hours spent playing was measured as the number of hours of online gaming in a week reported by the participant. Respondents took approximately $25 \mathrm{~min}$ to complete the survey.

In total, 827 participants started the survey. Four hundred and fourteen $(50.06 \%$ of the initial sample) completed the entire survey. Of these, 24 were excluded from analyses for the following reasons: no age reported $(n=8)$, anomalous hours of play $(n=1)$, inconsistent matches between item level and character level $(n=10)$, and impossible matches between character faction and character race $(n=5)$. The final sample consisted of 390 players. Participants' ages ranged from 18 to 67 years $(M=28.28, S D=8.24)$, and the sample was predominantly composed of men $(n=289$, $74.10 \%)$.

\section{Measures}

Difficulties in Emotion Regulation Scale (DERS-18). The DERS is a widely used self-report measure of emotion regulation difficulties. Items are rated on a scale from 1 (almost never) to 5 (almost always). Scores for each subscale and the total score are sums of the relevant items (with three items reverse-coded). Higher DERS scores reflect greater emotion regulation difficulties. In this study, we used the Italian translation (Sighinolfi, Norcini Pala, \& Chiri, 2010) of the 18-item version by Victor and Klonsky (2016). The DERS-18 includes six factor analytically derived subscales: lack of emotional awareness (Awareness; e.g., "I pay attention to how I feel," reverse scored; Cronbach's $\alpha=.68$ ); lack of emotional clarity (Clarity; e.g., "I am confused about how I feel;" Cronbach's $\alpha=.83$ ); lack of acceptance of one's emotions when distressed (Nonacceptance; e.g., "When I am upset, I feel ashamed with myself for feeling that way;" Cronbach's $\alpha=.83$ ); lack of ability to engage in goal-directed cognition and behavior when distressed (Goals; e.g., "When I am upset, I have difficulty focusing on other things;" Cronbach's $\alpha=.88$ ); lack of ability to manage one's impulses when distressed (Impulse; e.g., "When I am upset, I lose control of my behavior;" Cronbach's $\alpha=.88$ ); and lack of access to effective strategies for feeling better when distressed (Strategies; e.g., "When I am upset, I believe that I will remain that way for a long time;" Cronbach's $\alpha=.84$ ). Cronbach's $\alpha s$ for the subscales in this study were similar to those found in other studies (Estévez et al., 2017).

Internet Addiction Test - WoW Version (IAT-WoW). The IAT-WoW scale was used for assessing PG. The Italian translation of the IAT (Ferraro, Caci, D'Amico, \& Blasi, 2007) was adapted specifically for WoW rather than the Internet in general, in accordance with Billieux et al.'s (2013, 2015) suggestion. This adapted IAT comprised 20 items scored on a 5-point Likert scale measuring addictive use of WoW and related negative consequences on various aspects of everyday life (e.g., "Did you ever play WoW longer than you had intended?"). For each item, respondents can choose from five response options scored 1-5 (never, rarely, occasionally, often, and always). Higher IAT-WoW scores indicate higher levels of problematic involvement in WoW. Cronbach's $\alpha$ for IAT-WoW in this study was .88 , similar to that reported in other studies (Billieux et al., 2013, 2015).

Motivation to Play in Online Games Questionnaire (MPOGQ-WoWversion). The MPOGQ, developed by Yee (2006), measures the reasons why players engage in MMORPG. In this study, we adapted the original version to apply only to $\mathrm{WoW}$, in accordance with a procedure used by Billieux et al. (2013). The questionnaire measures three broad motivations divided into 10 specific motives: Achievement (advancement, competition, and mechanics), Social (socializing, relationship, and teamwork), and Immersion (customization, escapism, discovery, and roleplay). In accordance with the hypotheses of this study, only the escapism items were used. The escapism scale measures involvement in the video game to relax and/or to escape from real-life problems (e.g., "How often do you play WoW so that you can avoid thinking about some of your real-life problems or worries?"). Participants rate each statement using a 5-point Likert scale, with higher scores indicating higher escapism motives. Cronbach's $\alpha$ of the escapism scale in this study was .69, similar to that found in other studies (Billieux et al., 2013, 2015). 


\section{Measurement model}

We used a structural equation modeling (SEM) framework to test the hypothesis that escapism would mediate the relationship between ED and PG. This model is based on the notion that the six DERS subscales (Non-acceptance, Goal, Impulse, Awareness, Strategies, and Clarity) form the latent variable of ED. The three items comprising the escapism subscale of the MMOPGQ-WoW formed the latent variable of escapism. Since the IAT measure has shown inconsistent factor structures in previous research (Faraci, Craparo, Messina, \& Severino, 2013), we first ran an exploratory factor analysis on the IAT-WoW to identify a clear factor structure for our measurement model. Five factors had eigenvalues above 1 (the eigenvalues being $6.50,1.47,1.13,1.12$, and 1.07), but only the first factor explained more than $5 \%$ of the variance of the IAT-WoW (29.77\% of variance); moreover, solutions with more than one factor displayed significant and inconsistent loadings across factors. Therefore, we decided to use the five items with the highest loading on the general factor of the IATWoW to determine an appropriate measurement of PG and thus to form its latent factor. The five items selected to measure the IAT-WoW latent factor (items 2, 5, 12, 15, and 20; Cronbach's $\alpha=.76$ ) represent core symptoms of PG (neglecting household chores to spend more time online; others complaining about the amount of time spent on WoW; fears that life without WoW would be joyless; being preoccupied with WoW when offline and fantasizing about playing it; and feelings of depression or nervousness when not playing WoW, which go away when going back to playing it). Moreover, these items with the highest loadings on the IAT-WoW general factor are relevant for understanding PG patterns according to both the compensatory hypothesis of $\mathrm{PG}$ as a coping strategy to deal with current stressors (Kardefelt-Winther, 2014b) and to the symptom-based model of behavioral addictions (Brown, 1993; Griffiths, 2005). The measurement model and its predicted relationships between variables are depicted in Figure 1.

\section{Statistical analysis}

Descriptive statistics were calculated for all the variables in the study. Gender differences were examined using independent $t$-tests. Pearson's $r$ correlations between weekly hours of play and the psychological variables were also considered. SEM analysis of the measurement model was performed using the lavaan package (Rosseel, 2012) for $R$ software. Multiple goodness-of-fit indices were assessed. Assessment of the absolute indices included the following: the $\chi^{2} / d f$ ratio, for which values $\leq 2$ indicate a good fit; the root mean square error of approximation (RMSEA), for which values $\leq 0.05$ indicate a good fit; and the standardized root mean square residual (SRMR), for which a value $\leq 0.08$ is recommended for accepting a model. Assessment of incremental fit indices included the non-normed fit index (NNFI) and the comparative fit index (CFI), with values >.95 indicating a good fit for both (Brown, 2006; $\mathrm{Hu} \&$ Bentler, 1999). The $\chi^{2}$ test of difference was further used to determine whether the model presented in Figure 1 provided a better fit than did a non-mediated model in which ED independently predicted escapism and PG, without escapism mediating PG.

\section{Ethics}

The study was conducted in accordance with the Declaration of Helsinki and ethical guidelines for psychological research laid down by the Italian Psychological Association. All subjects were informed of the anonymity of the study and all gave their informed consent.

\section{RESULTS}

Descriptive statistics for the full sample and differentiated by gender are presented in Table 1 .

The majority of the players $(92.8 \%)$ had been playing WoW for more than 12 months, showing high game experience in terms of number of months played $(M=71.33$,

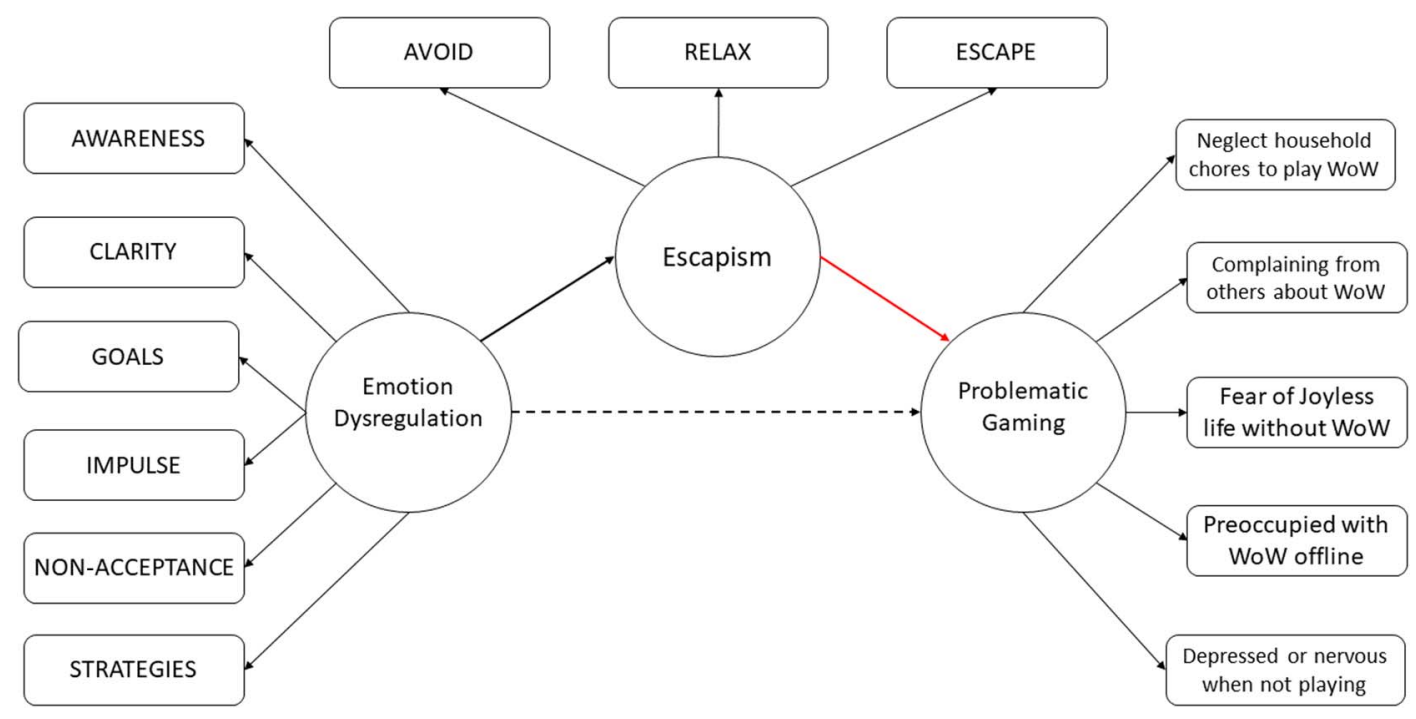

Figure 1. Measurement model 
Table 1. Psychosocial and game-related variables: Descriptive statistics and gender differences

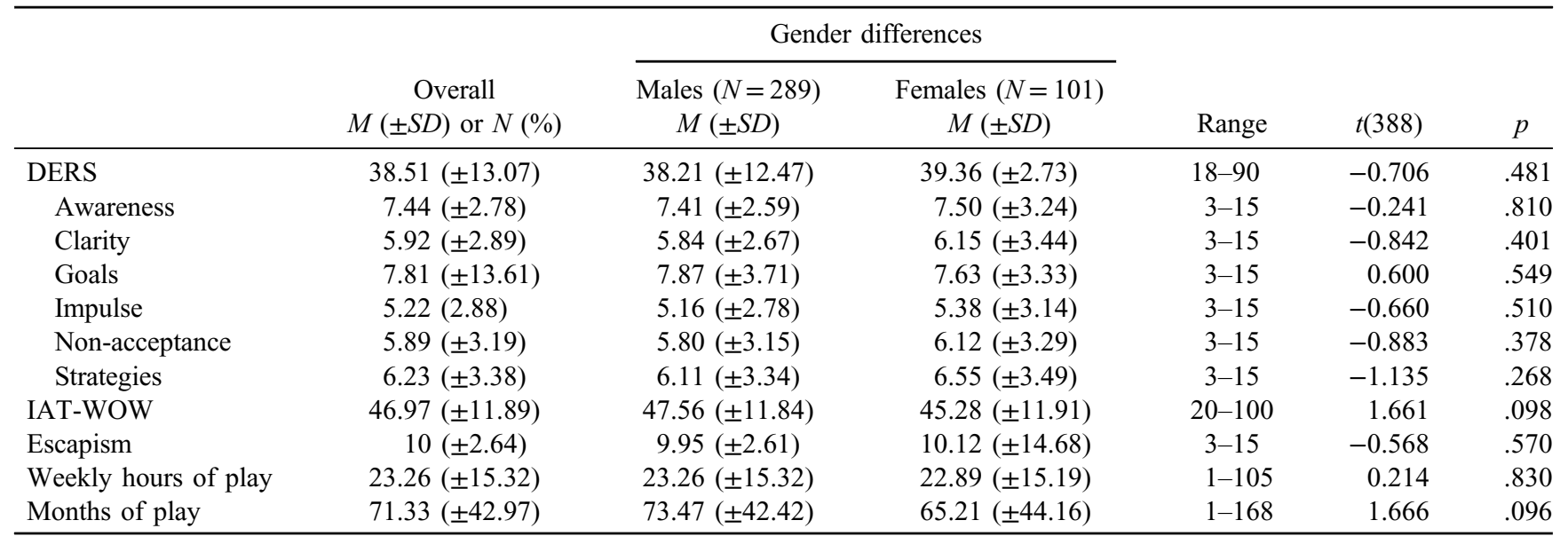

Note. M: mean; SD: standard deviation; DERS: Difficulties in Emotion Regulation Scale; IAT-WOW: Internet Addiction Test - World of Warcraft version.

$S D=42.97)$. On average, participants did not report high ED scores $(M=38.51, S D=13.07)$ with respect to other samples (Sighinolfi et al., 2010), although there was a slightly higher tendency to play to escape from reality $(M=10.00, S D=2.64)$ with respect to other studies (e.g., Kaczmarek \& Drążkowski, 2014). Moderate symptoms of PG were reported on the IAT-WOW $(M=46.97$, $S D=11.89$ ), similar to those found in other studies (Schimmenti, Infanti, et al., 2017; Wang et al., 2017).

The results of the $t$ tests examining gender differences showed that males did not differ significantly from females with regard to PG $[M=47.56, S D=11.84$ vs. $M=45.28$, $S D=11.91, \quad t(388)=1.661, p=.098], \quad \mathrm{ED} \quad[M=38.21$, $S D=12.47$ vs. $M=39.36, \quad S D=2.73, \quad t(388)=-0.70$, $p=.48]$, or escapism $[M=9.95, S D=2.61$ vs. $M=10.12$, $S D=4.68, t(388)=-0.56, p=.57]$. Nor did they differ in terms of weekly time spent playing WoW $[M=23.26$, $S D=15.32$ vs. $M=22.89, \quad S D=15.19, \quad t(388)=0.21$, $p=.83]$ or months since they had started to play $[M=73.47$, $S D=42.42$ vs. $M=65.21, \quad S D=44.16, \quad t(388)=1.66$, $p=.096]$. Pearson's $r$ correlations between age, weekly time spent playing WoW, and all the psychological measures are presented in Table 2.

ED was significantly and positively related to both PG and escapism, with relations being of moderate size. Notably, weekly hours spent playing was significantly, yet weakly, associated with escapism and PG but not with ED. Moreover, all the DERS subscales were significantly related to both PG and escapism motivations. Specifically, the strategies scale was the one mostly related to escapism motivations $(r=.40)$ and PG $(r=.33)$.

After examining the intercorrelations between variables, the model presented in Figure 1 was tested via SEM using maximum likelihood estimation. The model yielded a significant $\chi^{2}$ value $\left[\chi^{2}(74)=126.16, p<.001\right]$; however, the $\chi^{2} / d f$ ratio was 1.70 , suggesting a good fit. Further examination of fit indices confirmed that the mediation model fitted very well (RMSEA $=0.043$ [90\% CI: 0.029-0.055], $\mathrm{SRMR}=0.038, \mathrm{NNFI}=0.96, \mathrm{CFI}=0.97)$. All the estimates, intercepts, and variances in this model were significant at $p<.01$. The mediation model explained $31 \%$ of the escapism variance and $53 \%$ of the $\mathrm{PG}$ variance.

Table 2. Correlations between problematic involvement in WoW, escapism motives, and difficulties in emotion regulation with its dimensions

\begin{tabular}{|c|c|c|c|c|c|c|c|c|c|c|}
\hline Measures & 1 & 2 & 3 & 4 & 5 & 6 & 7 & 8 & 9 & 10 \\
\hline 1. Age & - & & & & & & & & & \\
\hline 2. Hours a week & -.02 & - & & & & & & & & \\
\hline 3. Escapism & $-.18 * * *$ & $.17 * * *$ & - & & & & & & & \\
\hline 4. IAT-WOW & $-.17 * * *$ & $.21 * * *$ & $.47 * * *$ & - & & & & & & \\
\hline 5. DERS total score & $-.30 * * *$ & .03 & $.43 * * *$ & $.39 * * *$ & - & & & & & \\
\hline 6. Awareness & -.02 & .07 & $.11^{* *}$ & $.12 * * *$ & $.40 * * *$ & - & & & & \\
\hline 7. Clarity & $-.27 * * *$ & -.03 & $.35^{* * *}$ & $.31 * * *$ & $.73 * * *$ & $.30 * * *$ & - & & & \\
\hline 8. Goals & $-.27 * * *$ & .00 & $.34 * * *$ & $.30 * * *$ & $.76^{* * *}$ & .05 & $.41 * * *$ & - & & \\
\hline 9. Impulse & $-.21 * * *$ & $.08 *$ & $.30 * * *$ & $.30 * * *$ & $.73 * * *$ & $.20 * * *$ & $.41 * * *$ & $.55 * * *$ & - & \\
\hline 10. Acceptance & $-.19 * * *$ & -.03 & $.29 * * *$ & $.25 * * *$ & $.70 * * *$ & $.15^{* * *}$ & $.40 * * *$ & $.46^{* * *}$ & $.37 * * *$ & - \\
\hline 11. Strategies & $-.27 * * *$ & .06 & $.40 * * *$ & $.33 * * *$ & $.80 * * *$ & $.12 * * *$ & $.54 * * *$ & $.57 * * *$ & $.52 * * *$ & $.50 * * *$ \\
\hline
\end{tabular}

Note. WoW: World of Warcraft; DERS: Difficulties in Emotion Regulation Scale; IAT-WOW: Internet Addiction Test - WoW version. ${ }^{*} p<.05 .{ }^{* *} p<.01 .{ }^{* * *} p<.001$. 


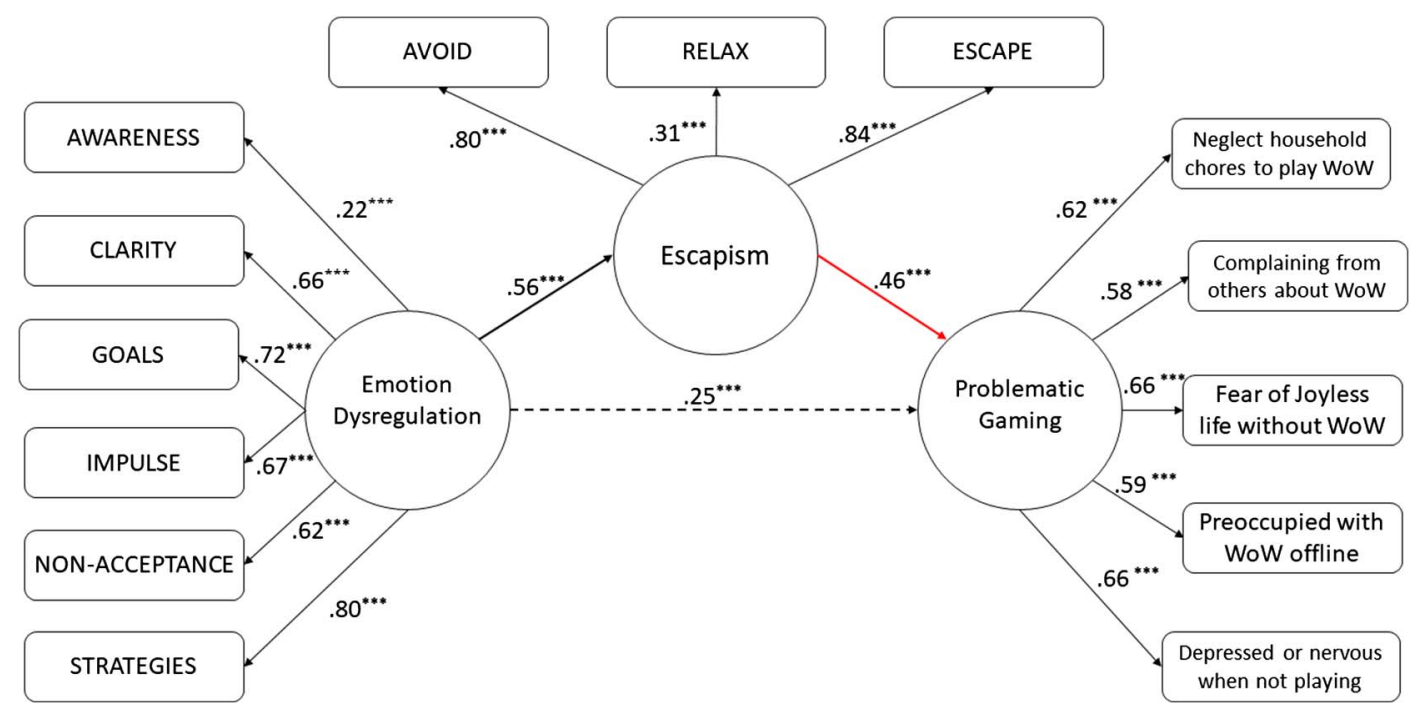

Figure 2. Mediation model. $\chi^{2}=126.16^{* * *}(d f=74)$; RMSEA $=0.043$ [90\% CI: $\left.0.029-0.055\right]$; SRMR $=0.038$; NNFI $=0.96$; $\mathrm{CFI}=0.97 . * * * p<.001$

The non-mediated model, in which ED predicted both escapism and PG with no relationship between these two latter variables, displayed only acceptable fit indices $($ RMSEA $=0.055$ [90\% CI: 0.044-0.067], SRMR $=0.060$, $\mathrm{NNFI}=0.96, \mathrm{CFI}=0.93$ ), and explained $37 \%$ of the escapism variance but only $36 \%$ of the PG variance. As expected, the mediation model was superior to the nonmediated model in which escapism did not mediate the predictive association between ED and PG $\left[\Delta \chi^{2}(1)=38.89\right.$, $p<.001]$. Notably, the effect of ED on PG decreased from a standardized estimate of $0.55(p<.001)$ in the non-mediated model to one of $0.26(p=.008)$, thus showing partial mediation of escapism in the relationship between ED and PG. The standardized total effect of the model was $0.51 \quad(p<.001)$; the standardized indirect effect of ED on PG via escapism was $0.26(p<.001)$. The standardized estimates of the mediation model are presented in Figure 2.

\section{DISCUSSION}

All our hypotheses were confirmed in our sample. Analyses conducted within an SEM framework showed that ED predicted both escapism motives and PG, and that escapism partially mediated this relationship. The fit indices of the mediation model were excellent and support the view that ED directly and indirectly affects levels of PG.

Consistent with $H l$, individuals reporting higher ED were more likely to show problematic involvement in WoW. This finding supports the view that ED is related to PG (Billieux et al., 2011; Estévez et al., 2017; Gaetan et al., 2016). Moreover, our results are consistent with other research showing that difficulties in emotion regulation are a part of, or give a rise to, psychological symptoms such as depression and social anxiety (Klemanski, Curtiss, McLaughlin, \& Nolen-Hoeksema, 2017; Paulus, Vanwoerden, Norton, \& Sharp, 2016), which have been established as risk factors for PG (Maroney et al., 2018; Yen et al., 2018).
Our findings are also well aligned with recent literature suggesting that video game environments are particularly suited to experimenting and coping with negative affect (Gaetan et al., 2016; Hemenover \& Bowman, 2018; Villani et al., 2018). For example, Gaetan et al. (2016, p. 347) suggested that video games may function as a means of rendering emotions psychologically meaningful and to "curb alexithymic dynamic;" that is, they can help gamers to reduce difficulties in identifying, describing, and processing their feelings (Schimmenti, Passanisi, et al., 2017). Nevertheless, for individuals who display difficulties in emotion regulation, the video game environment may be the main domain in which they can approach the regulation of their emotions without negative consequences (Billieux et al, 2015; Chang et al., 2018; Gaetan et al., 2016; Kardefelt-Winther, 2014b; Maroney et al. 2018; Schimmenti \& Caretti, 2010).

In accordance with our second hypothesis, our results showed higher ED to be associated with escapism. Previous studies have found an association between escapism motivation to play and negative emotions, as well as stressful life events (Hussain \& Griffiths, 2009; KardefeltWinter, 2014a, 2014c; Kuo et al., 2016). However, to our knowledge, this is the first study to focus on a potential underlying process, namely ED. As such, our findings are consistent with the results of Kuo et al. (2016) highlighting that escapism can act as a coping mechanism for WoW players motivated by the need to regulate their negative affect linked to external stressors. It could be argued that escapism in online games acts as an emotion-focused coping strategy aimed at better managing negative emotions and feelings. This strategy may paradoxically have the function of helping individuals to cope with the inefficacy or unavailability of other emotion regulation processes, thus allowing them temporarily to escape from negative mood states experienced in their offline lives through their immersion into alternative and more comfortable environments.

With regard to $H 3$, we found that escapism partially mediated the relationship between ED and PG. This 
observed mediating effect of escapism is also meaningful at the theoretical level, in which it shows that ED may lead individuals to use video games as either a "psychic retreat" from current and past problems (Schimmenti \& Caretti, 2010; Schimmenti, Guglielmucci, Barbasio, \& Granieri, 2012) and/or a coping strategy to escape from psychosocial stressors (Kardefelt-Winther, 2014b). However, the use of video games as a preferred strategy for coping with or escaping from psychological difficulties might foster excessive involvement in video games, and might eventually lead to clinically impairing gaming patterns. Similarly, a recent study (Maroney et al., 2018) found that escapism mediated the relationship between psychosocial distress and PG in a sample of online gamers. The results from this study suggest that, for gamers with higher ED, escapism might temporarily serve as an emotion-focused coping strategy for seeking temporary relief from disturbing affect states, while simultaneously exercising a "push" effect (Chang et al., 2018) that presses players into gaming to achieve short-term well-being, thus increasing the risk of PG.

Therefore, these results raise some relevant questions concerning the distinction between healthy and maladaptive escapism that need to be fleshed out. Indeed, many authors have shown that escapism motivations can be related to problematic gaming as well as highly engaged gaming, and that different psychological factors can interact with escapism to influence its functionality (Bowditch et al., 2018; Deleuze et al., 2018; Kardefelt-Winther, 2014c; Kuo et al., 2016). For example, Kuo et al. (2016) pointed out that while passive escapism provides relief from stressful emotions by simply refocusing attention on the fantastic narratives provided by the medium, active escapism may allow the gamer to directly confront specific psychological threats (e.g., low self-esteem) by redirecting awareness into an interactive fantasy world that can provide us with experiences of self-affirmation and empowerment. Accordingly, in our SEM, clear differences in the magnitude of loadings of the escapism items into their latent factor could be observed, suggesting that the escapism construct is multidimensional. Therefore, clarifying the nature of escapism as reflecting avoidant or active coping processes should be seen as a crucial task for future research on this topic. Overall, these findings call for the development of new measurement tools able to distinguish between adaptive versus maladaptive escapism in the context of video game playing.

\section{LIMITATIONS}

This study comes with some limitations that need to be acknowledged. First, it is a cross-sectional study, and therefore no causality can be inferred. Second, it relies on self-report measures, which can result in bias effects and under- or overreporting of behaviors. Third, the self-selected nature of the sample limits the ability to generalize our findings to other video game players (Khazaal et al., 2014). Fourth, partial attrition was high, with only $50 \%$ of initial participants completing the whole survey. Many respondents probably felt that the survey was too long, and as such a shorter survey may have counteracted this attrition. Finally, other psychosocial factors, such as social anxiety, depression, and social isolation, as well as other gaming motives that could play a role in PG, were not assessed. Therefore, future research using longitudinal designs and more representative samples of gamers are needed.

\section{CONCLUSIONS}

The findings of this study provide new information to support a better understanding of the psychological factors behind the development and maintenance of PG among WoW players. They suggest that escapism motivation in emotionally dysregulated individuals may strengthen PG. In line with a compensatory framework of PG (KardefeltWinther, 2014b; Schimmenti \& Caretti, 2010; Snodgrass et al., 2018), the findings also show the interplay between difficulties in emotion regulation, escapism, and problematic involvement in WoW. Furthermore, they provide evidence that gamers characterized by emotion regulation difficulties may rely on game experiences in order to regulate their emotional experiences, which can ultimately translate into a maladaptive coping strategy. While the deeply immersive nature of gaming experience can promote regulation of, and relief from, negative mood states, this maladaptive, emotionally focused coping strategy increases the risk of problematic involvement in video games. It is worth noting that this study also has some clinical implications. Problematic players, pushed by overwhelming emotions to escape into the video game, may benefit from interventions focused on enhancing their emotion regulation strategies and processes, such as those aimed at promoting interception and emotional awareness (Murphy, Brewer, Catmur, \& Bird, 2017) in order to reduce affect-laden impulsivity (Billieux, Gay, Rochat, \& Van der Linden, 2010) and strengthen mentalized affectivity (Schimmenti \& Caretti, 2010).

Funding sources: No financial support was received for this study.

Authors' contribution: All authors contributed equally to this work. They had full access to all data in the study and take responsibility for the integrity of the data and the accuracy of the data analysis.

Conflict of interest: The authors declare no conflict of interest.

\section{REFERENCES}

American Psychiatric Association. (2013). Diagnostic and statistical manual of mental disorders (DSM-5). Arlington, VA: American Psychiatric Association.

Ballabio, M., Griffiths, M. D., Urbán, R., Quartiroli, A., Demetrovics, Z., \& Király, O. (2017). Do gaming motives 
mediate between psychiatric symptoms and problematic gaming? An empirical survey study. Addiction Research \& Theory, 25(5), 397-408. doi:10.1080/16066359.2017.1305360

Beauchaine, T. P., Gatzke-Kopp, L., \& Mead, H. K. (2007). Polyvagal theory and developmental psychopathology: Emotion dysregulation and conduct problems from preschool to adolescence. Biological Psychology, 74(2), 174-184. doi:10.1016/j.biopsycho.2005.08.008

Billieux, J., Chanal, J., Khazaal, Y., Rochat, L., Gay, P., Zullino, D., \& Van der Linden, M. (2011). Psychological predictors of problematic involvement in massively multiplayer online roleplaying games: Illustration in a sample of male cybercafé players. Psychopathology, 44(3), 165-171. doi:10.1159/ 000322525

Billieux, J., Gay, P., Rochat, L., \& Van der Linden, M. (2010). The role of urgency and its underlying psychological mechanisms in problematic behaviours. Behaviour Research and Therapy, 48(11), 1085-1096. doi:10.1016/j.brat.2010.07.008

Billieux, J., Thorens, G., Khazaal, Y., Zullino, D., Achab, S., \& Linden, M. V. (2015). Problematic involvement in online games: A cluster analytic approach. Computers in Human Behavior, 43, 242-250. doi:10.1016/j.chb.2014.10.055

Billieux, J., Van der Linden, M., Achab, S., Khazaal, Y., Paraskevopoulos, L., Zullino, D., \& Thorens, G. (2013). Why do you play World of Warcraft? An in-depth exploration of self-reported motivations to play online and in game behaviours in the virtual world of Azeroth. Computers in Human Behavior, 29(1), 103-109. doi:10.1016/j.chb.2012.07.021

Bowditch, L., Chapman, J., \& Naweed, A. (2018). Do coping strategies moderate the relationship between escapism and negative gaming outcomes in World of Warcraft (MMORPG) players? Computers in Human Behavior, 86, 69-76. doi:10.1016/j.chb.2018.04.030

Brown, R. I. F. (1993). Some contributions of the study of gambling to the study of other addictions. In W. R. Eadington \& J. Cornelius (Eds.), Gambling behavior and problem gambling (pp. 241-272). Reno, NV: University of Nevada Press.

Brown, T. A. (2006). Confirmatory factor analysis for applied research. New York, NY: Guilford Press.

Casale, S., Caplan, S. E., \& Fioravanti, G. (2016). Positive metacognitions about Internet use: The mediating role in the relationship between emotional dysregulation and problematic use. Addictive Behaviors, 59, 84-88. doi:10.1016/ j.addbeh.2016.03.014

Chang, S. M., Hsieh, G. M., \& Lin, S. S. (2018). The mediation effects of gaming motives between game involvement and problematic Internet use: Escapism, advancement and socializing. Computers \& Education, 122, 43-53. doi:10.1016/ j.compedu.2018.03.007

D’Agostino, A., Covanti, S., Monti, M. R., \& Starcevic, V. (2017). Reconsidering emotion dysregulation. Psychiatric Quarterly, 88(4), 807-825. doi:10.1007/s11126-017-9499-6

David, S. (2016). Emotional agility: Get unstuck, embrace change, and thrive in work and life. London, UK: Penguin.

Deleuze, J., Long, J., Liu, T.-Q., Maurage, P., \& Billieux, J. (2018). Passion or addiction? Correlates of healthy versus problematic use of videogames in a sample of French-speaking regular gamers. Addictive Behaviors, 82, 114-121. doi:10.1016/ j.addbeh.2018.02.031
Demetrovics, Z., Urbán, R., Nagygyörgy, K., Farkas, J., Zilahy, D., Mervó, B., Reindl, A., Ágoston, C., Kertész, A., \& Harmath, E. (2011). Why do you play? The development of the Motives for Online Gaming Questionnaire (MOGQ). Behavior Research Methods, 43(3), 814-825. doi:10.3758/s13428-011-0091-y

Dimaggio, G., Popolo, R., Montano, A., Velotti, P., Perrini, F., Buonocore, L., Garofalo, C., D’Aguanno, M., \& Salvatore, G. (2017). Emotion dysregulation, symptoms, and interpersonal problems as independent predictors of a broad range of personality disorders in an outpatient sample. Psychology and Psychotherapy: Theory, Research and Practice, 90(4), 586-599. doi:10.1111/papt.12126

Elhai, J. D., Tiamiyu, M. F., Weeks, J. W., Levine, J. C., Picard, K. J., \& Hall, B. J. (2018). Depression and emotion regulation predict objective smartphone use measured over one week. Personality and Individual Differences, 133, 21-28. doi:10.1016/j.paid.2017.04.051

Estévez, A., Jáuregui, P., Sánchez-Marcos, I., López-González, H., \& Griffiths, M. D. (2017). Attachment and emotion regulation in substance addictions and behavioral addictions. Journal of Behavioral Addictions, 6(4), 534-544. doi:10.1556/ 2006.6.2017.086

Faraci, P., Craparo, G., Messina, R., \& Severino, S. (2013). Internet Addiction Test (IAT): Which is the best factorial solution? Journal of Medical Internet Research, 15(10), e225. doi:10.2196/jmir.2935

Ferraro, G., Caci, B., D’Amico, A., \& Blasi, M. D. (2007). Internet addiction disorder: An Italian study. CyberPsychology \& Behavior, 10(2), 170-175. doi:10.1089/cpb.2006.9972

Fonagy, P., Gergely, G., Jurist, E., \& Target, M. (2002). Affect regulation, mentalization, and the development of the self. New York, NY: Other Press.

Gaetan, S., Bréjard, V., \& Bonnet, A. (2016). Video games in adolescence and emotional functioning: Emotion regulation, emotion intensity, emotion expression, and alexithymia. Computers in Human Behavior, 61, 344-349. doi:10.1016/ j.chb.2016.03.027

Griffiths, M. (2005). A 'components' model of addiction within a biopsychosocial framework. Journal of Substance Use, 10(4), 191-197. doi:10.1080/14659890500114359

Gross, J. J., \& Jazaieri, H. (2014). Emotion, emotion regulation, and psychopathology: An affective science perspective. Clinical Psychological Science, 2(4), 387-401. doi:10.1177/ 2167702614536164

Gross, J. J., \& Thompson, R. A. (2007). Emotion regulation: Conceptual foundations. In J. J. Gross (Ed.), Handbook of emotion regulation (pp. 3-24). New York, NY: Guilford Press.

Hemenover, S. H., \& Bowman, N. D. (2018). Video games, emotion, and emotion regulation: Expanding the scope. Annals of the International Communication Association, 42(2), 125-143. doi:10.1080/23808985.2018.1442239

Hoffner, C. A., \& Lee, S. (2015). Mobile phone use, emotion regulation, and well-being. Cyberpsychology, Behavior, and Social Networking, 18(7), 411-416. doi:10.1089/cyber. 2014.0487

Hormes, J. M., Kearns, B., \& Timko, C. A. (2014). Craving Facebook? Behavioral addiction to online social networking and its association with emotion regulation deficits. Addiction, 109(12), 2079-2088. doi:10.1111/add.12713 
Hu, L. T., \& Bentler, P. M. (1999). Cutoff criteria for fit indexes in covariance structure analysis: Conventional criteria versus new alternatives. Structural Equation Modeling, 6(1), 1-55. doi: $10.1080 / 10705519909540118$

Hussain, Z., \& Griffiths, M. D. (2009). The attitudes, feelings, and experiences of online gamers: A qualitative analysis. CyberPsychology \& Behavior, 12(6), 747-753. doi:10.1089/ cpb.2009.0059

Kaczmarek, L. D., \& Drążkowski, D. (2014). MMORPG escapism predicts decreased well-being: Examination of gaming time, game realism beliefs, and online social support for offline problems. Cyberpsychology, Behavior, and Social Networking, 17(5), 298-302. doi:10.1089/cyber.2013.0595

Kardefelt-Winther, D. (2014a). Problematizing excessive online gaming and its psychological predictors. Computers in Human Behavior, 31, 118-122. doi:10.1016/j.chb.2013.10.017

Kardefelt-Winther, D. (2014b). A conceptual and methodological critique of Internet addiction research: Towards a model of compensatory Internet use. Computers in Human Behavior, 31, 351-354. doi:10.1016/j.chb.2013.10.059

Kardefelt-Winther, D. (2014c). The moderating role of psychosocial well-being on the relationship between escapism and excessive online gaming. Computers in Human Behavior, 38, 68-74. doi:10.1016/j.chb.2014.05.020

Khazaal, Y., van Singer, M., Chatton, A., Achab, S., Zullino, D., Rothen, S., Khan, R., Billieux, J., \& Thorens, G. (2014). Does self-selection affect samples' representativeness in online surveys? An investigation in online video game research. Journal of Medical Internet Research, 16(7), e164. doi:10.2196/jmir.2759

King, D. L., Delfabbro, P. H., Potenza, M. N., Demetrovics, Z., Billieux, J., \& Brand, M. (2018). Internet gaming disorder should qualify as a mental disorder. Australian \& New Zealand Journal of Psychiatry, 52(7), 615-617. doi:10.1177/ 0004867418771189

Király, O., Urbán, R., Griffiths, M. D., Ágoston, C., Nagygyörgy, K., Kökönyei, G., \& Demetrovics, Z. (2015). Psychiatric symptoms and problematic online gaming: The mediating effect of gaming motivation. Journal of Medical Internet Research, 17(4), e88. doi:10.2196/jmir.3515

Klemanski, D. H., Curtiss, J., McLaughlin, K. A., \& NolenHoeksema, S. (2017). Emotion regulation and the transdiagnostic role of repetitive negative thinking in adolescents with social anxiety and depression. Cognitive Therapy and Research, 41(2), 206-219. doi:10.1007/s10608-016-9817-6

Kuo, A., Lutz, R., \& Hiler, J. (2016). Brave new World of Warcraft: A conceptual framework for active escapism. Journal of Consumer Marketing, 33(7), 498-506. doi:10.1108/ JCM-04-2016-1775

Kuss, D. J., Louws, J., \& Wiers, R. W. (2012). Online gaming addiction? Motives predict addictive play behavior in massively multiplayer online role-playing games. Cyberpsychology, Behavior, and Social Networking, 15(9), 480-485. doi:10.1089/cyber.2012.0034

Maroney, N., Williams, B. J., Thomas, A., Skues, J., \& Moulding, R. (2018). A stress-coping model of problem online video game use. International Journal of Mental Health and Addiction. Advance online publication. 1-14. doi:10.1007/ s1146

Murphy, J., Brewer, R., Catmur, C., \& Bird, G. (2017). Interoception and psychopathology: A developmental neuroscience perspective. Developmental Cognitive Neuroscience, 23, 45-56. doi:10.1016/j.den.2016.12.006

Paulus, D. J., Vanwoerden, S., Norton, P. J., \& Sharp, C. (2016). Emotion dysregulation, psychological inflexibility, and shame as explanatory factors between neuroticism and depression. Journal of Affective Disorders, 190, 376-385. doi:10.1016/ j.jad.2015.10.014

Petry, N. M., Rehbein, F., Gentile, D. A., Lemmens, J. S., Rumpf, H. J., Mößle, T., Bischof, G., Tao, R., Fung, D. S., Borges, G., Auriacombe, M., González Ibáñez, A., Tam, P., \& O’Brien, C. P. (2014). An international consensus for assessing Internet gaming disorder using the new DSM-5 approach. Addiction, 109(9), 1399-1406. doi:10.1111/add.12457

Reinecke, L. (2009). Games and recovery: The use of video and computer games to recuperate from stress and strain. Journal of Media Psychology, 21(3), 126-142. doi:10.1027/18641105.21.3.126

Rosseel, Y. (2012). lavaan: An R package for structural equation modeling. Journal of Statistical Software, 48(2), 1-36. doi:10.18637/jss.v048.i02

Schimmenti, A., \& Caretti, V. (2010). Psychic retreats or psychic pits? Unbearable states of mind and technological addiction. Psychoanalytic Psychology, 27(2), 115-132. doi:10.1037/ a0019414

Schimmenti, A., Guglielmucci, F., Barbasio, C., \& Granieri, A. (2012). Attachment disorganization and dissociation in virtual worlds: A study on problematic Internet use among players of online role-playing games. Clinical Neuropsychiatry, 9(5), 187-195.

Schimmenti, A., Infanti, A., Badoud, D., Laloyaux, J., \& Billieux, J. (2017). Schizotypal personality traits and problematic use of massively-multiplayer online role-playing games (MMORPGs). Computers in Human Behavior, 74, 286-293. doi:10.1016/j.chb.2017.04.048

Schimmenti, A., Passanisi, A., Caretti, V., La Marca, L., Granieri, A., Iacolino, C., Gervasi, A. M., Maganuco, N. R., \& Billieux, J. (2017). Traumatic experiences, alexithymia, and Internet addiction symptoms among late adolescents: A moderated mediation analysis. Addictive Behaviors, 64, 314-320. doi:10.1016/j.addbeh.2015.11.002

Schimmenti, A., Starcevic, V., Gervasi, A. M., Deleuze, J., \& Billieux, J. (2018). Interference with processing negative stimuli in problematic Internet users: Preliminary evidence from an emotional Stroop task. Journal of Clinical Medicine, 7(7), 177. doi:10.3390/jcm7070177

Sighinolfi, C., Norcini Pala, A., \& Chiri, L. R. (2010). Difficulties in Emotion Regulation Scale: Traduzione e adattamento Italiano. Psicoterapia Cognitiva e Comportamentale, 16(2), 141-170.

Snodgrass, J. G., Bagwell, A., Patry, J. M., Dengah II, H. F., Smarr-Foster, C., Van Oostenburg, M., \& Lacy, M. G. (2018). The partial truths of compensatory and poor-get-poorer Internet use theories: More highly involved videogame players experience greater psychosocial benefits. Computers in Human Behavior, 78, 10-25. doi:10.1016/j.chb.2017.09.020

Snodgrass, J. G., Lacy, M. G., Dengah II, H. F., Eisenhauer, S., Batchelder, G., \& Cookson, R. J. (2014). A vacation from your mind: Problematic online gaming is a stress response. Computers in Human Behavior, 38, 248-260. doi:10.1016/ j.chb.2014.06.004

Van Rooij, A. J., Ferguson, C. J., Colder Carras, M., KardefeltWinther, D., Shi, J., Aarseth, E., Bean, A. M., Bergmark, K. H., 
Brus, A., Coulson, M., Deleuze, J., Dullur, P., Dunkels, E., Edman, J., Elson, M., Etchells, P. J., Fiskaali, A., Granic, I., Jansz, J., Karlsen, F., Kaye, L. K., Kirsh, B., Lieberoth, A., Markey, P., Mills, K. L., Nielsen, R. K. L., Orben, A., Poulsen, A., Prause, N., Prax, P., Quandt, T., Schimmenti, A., Starcevic, V., Stutman, G., Turner, N. E., van Looy, J., \& Przybylski, A. K. (2018). A weak scientific basis for gaming disorder: Let us err on the side of caution. Journal of Behavioral Addictions, 7(1), 1-9. doi:10.1556/2006.7.2018.19

Victor, S. E., \& Klonsky, E. D. (2016). Validation of a brief version of the Difficulties in Emotion Regulation Scale (DERS-18) in five samples. Journal of Psychopathology and Behavioral Assessment, 38(4), 582-589. doi:10.1007/s10862-016-9547-9

Villani, D., Carissoli, C., Triberti, S., Marchetti, A., Gilli, G., \& Riva, G. (2018). Videogames for emotion regulation: A systematic review. Games for Health Journal, 7(2), 85-99. doi:10.1089/g4h.2017.0108

Wang, L., Wu, L., Wang, Y., Li, H., Liu, X., Du, X., \& Dong, G. (2017). Altered brain activities associated with craving and cue reactivity in people with Internet gaming disorder: Evidence from the comparison with recreational Internet game users. Frontiers in Psychology, 8, 1150. doi:10.3389/fpsyg.2017.01150

World Health Organization. (2018). ICD-11 for mortality and morbidity statistics. Retrieved from https://icd.who.int/ browse11/1-m/en\#/http://id.who.int/icd/entity/1448597234

Yee, N. (2006). Motivation for play in online games. CyberPsychology \& Behavior, 9(6), 772-775. doi:10.1089/cpb.2006.9.772

Yen, J. Y., Yeh, Y. C., Wang, P. W., Liu, T. L., Chen, Y. Y., \& Ko, C. H. (2018). Emotional regulation in young adults with Internet gaming disorder. International Journal of Environmental Research and Public Health, 15(1), 30. doi:10.3390/ijerph15010030

Yildiz, M. A. (2017). Emotion regulation strategies as predictors of Internet addiction and smartphone addiction in adolescents. Journal of Educational Sciences and Psychology, 7(1), 66-78.

Zanetta-Dauriat, F., Zermatten, A., Billieux, J., Thorens, G., Bondolfi, G., Zullino, D., \& Khazaal, Y. (2011). Motivations to play specifically predict excessive involvement in massively multiplayer online role-playing games (MMORPGs): Evidence through an online survey. European Addiction Research, 17, 185-189. doi:10.1159/000326070 